\title{
A FÓRMULA “DESLEGITIMAÇÃO DE ISRAEL" ENTRE POLÊMICA INTRÍNSECA E ARGUMENTAÇÃO POLÊMICA ${ }^{i}$
}

\author{
Nadia Ellis
}

Resumo: Neste artigo, buscamos voltar nossa atenção para uma das características principais da fórmula, a saber: seu caráter polêmico. Tendo em vista a natureza politética das unidades lexicais que compõem a fórmula, uma polêmica se desencadeia muitas vezes sobre a própria significação de uma fórmula. Ao mesmo tempo, uma fórmula também pode ser mobilizada em uma argumentação de caráter polêmico, utilizada para levar a cabo sua missão de persuasão. Assim, podemos nos indagar sobre a relação entre o caráter intrinsecamente polêmico de uma fórmula e sua exploração no centro de uma confrontação verbal de caráter polêmico. Este estudo dedica-se mais particularmente ao emprego da fórmula "deslegitimação de Israel" nos discursos políticos, para ver como essa fórmula pode ser explorada por diferentes atores políticos para desqualificar o discurso de seu adversário (ou ainda para obter um consenso junto a seu público) durante uma confrontação entre posições antagonistas. Como a polemicidade inerente a esta fórmula pode ser explorada na construção polêmica em geral e política em particular?iii.

Palavras-chave: Polêmica. Deslegitimação. Israel. Fórmula. Desqualificação.

Abstract: In this article we wish to concentrate our attention on one of the main characteristics of a formula, i.e. its polemical aspect. Because of the often polythetic nature of the lexical units that compose it, in fact, polemics often rise around the very meaning of a formula. At the same time, a formula can also be used in a polemical argumentation, which exploits it in order to achieve its persuasion goals. We can therefore ask ourselves whether there is a connection between the intrinsic polemical aspect of a formula and its use at the heart of a polemical verbal confrontation. This study specifically concentrates on the uses of the formula "delegitimization of Israel" in political speeches, in order to verify how it can be used by different political actors with the goal of disqualifying the speech of their adversary (or in order to obtain their own public's consensus) during a confrontation between antagonistic positions. How can the inherent polemical aspect of this formula be exploited in the construction of polemical argumentation in general, and political polemical argumentation in particular?

Keywords: Polemics. Delegitimization. Israel. Formula. Disqualification.

i Este trabalho tem sido realizado no projeto de pesquisa sobre "A deslegitimação de Israel: os usos políticos e retórico de uma fórmula na França “. Projeto 186/12, sob a responsabiliade de Ruth Amossy e Denis Charbit, com apoio da Israel Science Foundation.

ii Doutora pela Universidade de Tel Aviv, Israel. E-mail: ellisnad@gmail.com.

iii NT: Embora o resumo de artigos acadêmicos seja orientado pela ABNT, nesta edição especial, optamos por manter o padrão proposto pelos autores na versão original, em francês. 
EID\&A - Revista Eletrônica de Estudos Integrados em Discurso e Argumentação, Ilhéus, n. esp. ADARR, mai.2016.

\section{Introdução}

Os estudos linguísticos e discursivos das últimas décadas chamam a atenção para a existência de expressões que entram no debate público de maneira bastante repentina e ao mesmo tempo de uma forma que parece evidente aos locutores. Recentemente conceituadas por Alice Krieg-Planque, as fórmulas são lexemas ou sequências de lexemas que se cristalizam na atividade discursiva pública (em todos os seus níveis) em certo momento histórico e que "ganham vida" enquanto unidades de sentido, embora sua significação não seja justamente unívoca nem unanimemente estabelecida.

Neste artigo, voltamos nossa atenção para uma das principais características da fórmula: o caráter polêmico. Tendo em vista a natureza politética das unidades lexicais que compõem a fórmula, uma polêmica desencadeia-se muitas vezes sobre a própria significação de uma fórmula. Ao mesmo tempo, uma fórmula também pode ser mobilizada em uma argumentação de caráter polêmico, utilizada para levar a cabo sua missão de persuasão. Então, podemos nos indagar sobre a relação entre o caráter intrinsecamente polêmico de uma fórmula, que carrega seu próprio sentido e sua própria pertinência, e sua exploração em um confronto verbal, em que ela não é um fim em si mesma (não se trata de fazê-la sobressair), mas é uma arma argumentativa posta a serviço de diversos objetivos. Como a polemicidade inerente à fórmula pode ser explorada na construção da argumentação polêmica em geral e política em particular?

Nosso estudo concentra-se no emprego da fórmula "deslegitimação de Israel", que, desde os anos 2000, tornou-se moeda corrente em Israel e na comunidade judia diaspórica, figurando abundantemente no discurso corrente israelense, bem como em todo tipo de discurso que toca no assunto de Israel e sua legitimidade. $O$ estudo em questão examina a utilização da fórmula nos discursos políticos, para ver como esta pode ser explorada por diferentes atores políticos para desqualificar o discurso de seu adversário (ou ainda para obter um consenso junto a seu público) durante a confrontação entre posições antagonistas. Apresentaremos, inicialmente, as noções de polêmica pública e de fórmula, para estudá-las em seguida num debate sobre a fórmula “deslegitimação de Israel”, posteriormente sobre uma polêmica política, a qual faz uso da referida fórmula para desacreditar o adversário. 
EID\&A - Revista Eletrônica de Estudos Integrados em Discurso e Argumentação, Ilhéus, n. esp. ADARR, mai.2016.

\section{A polêmica}

Numerosos estudos têm sido publicados a propósito da polêmica, e a tarefa de considerar todos eles é de suma importância para este artigo. Propomos então uma breve síntese das maneiras como a polêmica é geralmente definida pelos estudos contemporâneos de argumentação e de análise do discurso, para, em seguida, passar à análise dos textos selecionados.

De maneira geral, pode-se definir a polêmica como uma confrontação verbal na qual o assunto debatido tem um interesse público - sem isso, tratase de uma querela de ordem privada (PLANTIN, 2003). A polêmica se define então pela presença de um discurso A contra um discurso B: "O que caracteriza antes de tudo o fenômeno é que ele se inscreve em um espaço dialógico no qual ele constitui "um discurso a contrario" (MARCELLESI, 1971, p. 44); a polêmica é "um contradiscurso" (KERBRAT-ORECCHIONI, 1980, p. 9); ela supõe "um contradiscurso antagonista" (ANGENOT, 1982, p. 34) que se detém sobre o discurso do outro para rejeitá-lo" (AMOSSY; BURGER, 2011, p.11). O discurso polêmico é necessariamente dialógico, pois:

[...] toma sempre por objeto um discurso outro e traz julgamentos de valor sobre este. Neste sentido, pode-se dizer que os locutores engajados em uma polêmica fazem uso do poder de reflexibilidade das línguas naturais: eles sustentam discursos sobre outros discursos" (MICHELI, 2011, p. 2).

No entanto, ele não é forçosamente dialogal'. Essa é a diferença que Amossy (2014) estabelece entre discurso polêmico e troca polêmica. A polêmica presume então um discurso adverso ao qual ela se opõe por uma argumentação mais ou menos violenta, cuja finalidade é sempre desacreditar o outro e suas posições: "O discurso polêmico é um discurso desqualificante, quer dizer, que ataca um alvo" (KERBRAT-ORECCHIONI, 1980, p. 12). Se "Os enunciados adversos são

\footnotetext{
1 Jacques Bres (2005, p. 47-61) explica a diferença entre os termos dialogal e dialógico, assim:

“- dialogal, para se encarregar de tudo o que se refere ao diálogo enquanto alternância de atos de fala, digamos o diálogo externo, para falar como Bakhtin; dialogal se opõe à monologal”;

“- dialógico, para se encarregar da problemática da orientação do enunciado em direção a outros enunciados, digamos para chegar ao diálogo interno; dialógico se opõe a monológico. Cumpre salientar que dialógico é antão percebido mais como a tradução do termo russo dialogicheskij, oriundo dos trabalhos de Bakhtin, que como um neologismo de sentido a partir do adjetivo francês dialógico. Da mesma maneira que o substantivo dialogismo é, antes, percebido como a tradução do russo dialogichnost que como neologismo de sentido da figura retórica que traz esse substantivo, e que Fontanier (1977 [1821]) define assim: o dialogismo consiste em relacionar diretamente, tal como são esperados a sair da boca, os discursos que se emprestam às personagens ou a nós mesmos em um ou outra circunstância".
} 
EID\&A - Revista Eletrônica de Estudos Integrados em Discurso e Argumentação, Ilhéus, n. esp. ADARR, mai.2016.

necessariamente convidados, [...] é para melhor anulá-los" (MAINGUENEAU, 1983, p. 16).

Se a desqualificação do adversário pode ser feita por meio do descrédito lançado sobre seus argumentos, mas também (e frequentemente) sobre a própria pessoa do adversário (em que há o emprego quase onipresente, na polêmica, do argumento ad hominem), podemos nos questionar se esta desqualificação tem por finalidade aumentar o consenso em torno da pessoa do locutor e de suas posições (o que faria a polêmica ingressar com todo direito no domínio da argumentação) ou se ela é apenas uma forma de confrontação violenta entre seres humanos, em um enfrentamento de visões opostas ao ponto de elas serem irreconciliáveis (ANGENOT, 2008; DASCAL, 2006; DASCAL \& KNOLL, 2011). Entretanto, mesmo se ela seja apenas a forma "civilizada" da confrontação violenta outrora desenvolvida pelos diferentes meios do combate físico, a polêmica comporta um traço suplementar: ela permite, na sociedade contemporânea, como mostra Amossy, uma (muito importante) coexistência no dissenso:

\begin{abstract}
A argumentação muda então de rumo. Ela renuncia a seu ideal de acordo e de colaboração cedendo às pressões do meio que o tornam impraticável. Ao mesmo tempo, ela preenche uma função social: ela autoriza, por meio da interação verbal, uma coexistência no dissenso. Em um espaço em que a gestão verbal dos conflitos ameaça sempre se transformar em violência armada, admitir-se-á que esse objetivo talvez não seja tão modesto como poderia parecer à primeira vista. (AMOSSY, 2011, p. 2).
\end{abstract}

Mas a polêmica parece pertencer também, e de pleno direito, ao domínio da argumentação, pois, se consideramos que, ao lado do (e por meio do) descrédito lançado sobre o outro e suas posições, o locutor se compromete igualmente em um esforço de persuasão, isso estaria tão somente no próprio campo da argumentação.

Para Amossy (2010), que vê na argumentação um continuum que vai da co-construção das respostas ao confronto violento das teses antagonistas, a polêmica constitui um dos polos da atividade argumentativa. É então a forma segundo a qual os argumentos são construídos e opostos, a maneira como os argumentos são integrados nos discursos mutuamente hostis, que devem ser ainda mais exploradas para fundamentar em provas o pertencimento da polêmica no domínio da argumentação (AMOSSY \& BURGER, 2011, p. 14).

Outra característica, a argumentação polêmica passa frequentemente pela violência verbal e pela ênfase na emoção. Não se trata somente da 
EID\&A - Revista Eletrônica de Estudos Integrados em Discurso e Argumentação, Ilhéus, n. esp. ADARR, mai.2016.

presença do pathos (a tentativa de sensibilizar o auditório pode também se realizar por uma argumentação não violenta), mas também dos "fortes traços de afetividade que se inscrevem em uma fala subjetiva e manifestam o estado de espírito do orador" (Ibidem). Sendo isto, na medida em que a polêmica é uma prática social ao mesmo tempo em que é uma prática retórica, numerosos esforços são igualmente investidos na construção de uma identidade social por meio da qual se apresenta suas posições. Nesse caso, os apelos ao pathos podem ser interpretados como uma busca pela empatia do público, para melhor transformá-lo em militantes de sua causa.

É justamente o público como um Terceiro que constitui o último aspecto geralmente reconhecido como o que caracteriza as trocas polêmicas (PLANTIN, 2003): enquanto a polêmica em si pode se desenvolver no interior de uma troca entre apenas duas pessoas, é a presença (não necessariamente no momento em que a polêmica se desenvolve) de um público sensibilizado por suas implicações e suas consequências que coloca plenamente a polêmica no espaço do debate público. Vários estudos investigaram o papel das mídias na difusão (e às vezes a própria criação) das polêmicas contemporâneas (cf. BURGER, 2011), mas esse assunto extrapola o objetivo deste estudo, o qual se propõe a analisar o funcionamento de uma fórmula no interior de uma argumentação polêmica.

\section{A fórmula como intrinsecamente polêmica e/ou como arma argumentativa na polêmica}

A unidade lexical complexa "deslegitimação de Israel" responde aos quatro critérios definidores de uma fórmula, tais como postulados por Alice Krieg-Planque (2009). Em primeiro lugar, trata-se de uma unidade lexical cristalizada. De fato, no espaço público de discussão israelense, da diáspora e dos intelectuais especializados no assunto, a sequência é conhecida por todos em sua forma cristalizada e, parafraseando a autora, é justamente porque "se a fórmula existe também por meio de suas paráfrases, ela não existe fora de uma sequência cristalizada bem identificada que as condensa" (Ibidem, p. 69). Em segundo lugar, essa unidade lexical se inscreve em uma dimensão discursiva e é graças a seus numerosos empregos em todo tipo de discurso que esta sequência cristalizou-se e se tornou um jogo de posições. Em terceiro lugar, a fórmula em estudo funciona como um referente social: o público israelense e o público judeu diaspórico empregam a sequência 
EID\&A - Revista Eletrônica de Estudos Integrados em Discurso e Argumentação, Ilhéus, n. esp. ADARR, mai.2016.

"deslegitimação de Israel" sem que haja necessidade de explicar do que se trata, o que poderia levar a pensar em um consenso sobre sua significação. Entretanto, considerando a natureza politética das unidades lexicais empregadas, "palavras complexas, que, sem redução, não se deixam encaixar em uma definição do tipo convencional" (BOUDON, 1995, p. 535), o consenso em questão é apenas ilusório. Assim, a quarta característica é que a fórmula carrega uma característica polêmica que muitas vezes diz respeito ao próprio significado da unidade lexical e também "porque ela carrega um valor de descrição dos fatos políticos e sociais" (KRIEG-PLANQUE, 2009, p. 104): "deslegitimação de Israel” implica problemas sociopolíticos importantes que podem ser facilmente destacados nas argumentações (polêmicas) que empregam essa fórmula. Entre as quatro características da fórmula listadas acima, é o caráter polêmico que nos interpela no contexto deste artigo. A polêmica recobre aqui um duplo papel no sentido em que não é apenas o caráter intrinsecamente polêmico da fórmula que nos interessa, mas também a possibilidade que ela apresenta de criar uma argumentação polêmica.

Uma fórmula, de fato, se caracteriza pela indefinição inerente à sua significação, "recurso que a língua oferece a seus utilizadores" (KRIEGPLANQUE, 2012, p. 155). Entre os atributos que permitem a uma fórmula penetrar no discurso público muito rapidamente, a indefinição é, sem dúvida, indispensável naquilo que ela permite aos locutores (tanto quanto à audiência) interpretarem a significação da fórmula de diferentes maneiras e, assim, as inserirem em argumentações muito variadas participando, desse modo, de sua rápida difusão.

Como já explicamos em um artigo anterior (ELLIS, 2014), no caso específico da fórmula "deslegitimação de Israel", o ato de nominalização do verbo "deslegitimar" cria condições de indefinição particularmente propícias, pois ela torna facultativas as menções de tempo, de modo e de actantes implicados em um processo do qual ela não é mais que o resto e do qual ela pode se autorizar a apenas levar em conta de forma incompleta, uma vez que, por nominalização de ação, designam-se nomes que são oriundos de um processo do qual eles são - ou ao menos, no plano semântico, parecem ser - a transformação (cf. KRIEG-PLANQUE, 2012, p. 209-210).

Assim, o verbo "deslegitimar" designa a ação de remover a legitimidade (de alguma coisa ou de alguém), enquanto que a legitimidade em questão pode ser abrangida pelo direito (por exemplo, uma criança "legítima" é uma 
EID\&A - Revista Eletrônica de Estudos Integrados em Discurso e Argumentação, Ilhéus, n. esp. ADARR, mai.2016.

criança nascida em um contexto de igualdade) ou pelos modos de vida (uma questão "legítima" é uma questão moralmente válida, justificada). Nesta distinção que não encontra expressão na nominalização do verbo, a fórmula mantém intrinsecamente o lugar de duas ações para problemas muito diferentes. Paralelamente, a indeterminação que dá origem à nominalização diz respeito também ao objeto indireto da ação referida, objeto cujas facetas são múltiplas e nunca levadas em conta ao mesmo tempo: qual parte do campo semântico de "Israel" é o objeto da deslegitimação?

O nome de um país é, de fato, portador de um sentido que está longe de ser unívoco: o topônimo é um "determinante dotado de uma multirreferencialidade que implica sua polissemia" (PAVEAU, 2008, p. 23), o que significa que o signo "Israel" se refere a uma variedade de significações que são influenciados pelo contexto sociocultural do locutor e de seu auditório, assim como pelo momento histórico no qual a produção verbal se realiza. Esta atitude na "multirreferencialidade" permite igualmente uma semiotização particular de conteúdos simbólicos variados (CISLARU, 2005).

O topônimo não desempenha somente uma denominação geográfica, mas desenha caminhos semânticos complexos, contingentes e às vezes originais, por meio dos contextos culturais, identitários, afetivos e memoriais de um sujeito ou de um grupo (PAVEAU, 2008, p.23).

E, ainda, graças ao recurso da metonímia, um mesmo topônimo pode designar a entidade geográfica, ou a nação, ou o governo, ou uma equipe de futebol e assim sucessivamente. Além disso, a denominação de um topônimo "se tinge de ideologia" (GRASS, 2006). Assim, o topônimo "Israel” pode ser facilmente carregado de uma longa série de influências que vai do contexto geopolítico, passando pelo sentimento de pertencimento ou a rejeição total, até os efeitos de sentido obtidos pela hipermidiatização do conflito IsraelPalestino. "O sentido polimorfo estando fixado no e pelo discurso, apenas um contexto discursivo é suscetível de nos dar a configuração semântica dos nomes de país" (CISLARU, 2005, p. 121).

A indefinição que acabamos de descrever é particularmente significativa no contexto de uma análise do aspecto polêmico da fórmula, pois, como veremos no primeiro de nossos três exemplos, uma troca polêmica concernente à "deslegitimação de Israel" pode, perfeitamente, se concentrar na significação dos mesmos lexemas que compõem a fórmula e na existência do fenômeno descrito por esta fórmula. Ao mesmo tempo, essa mesma 
EID\&A - Revista Eletrônica de Estudos Integrados em Discurso e Argumentação, Ilhéus, n. esp. ADARR, mai.2016.

indefinição pode permitir o emprego da fórmula em todos os tipos de argumentações polêmicas e isso graças à sua extrema flexibilidade de sentido. Veremos ainda nos dois outros exemplos como a fluidez interpretativa da fórmula permite seu emprego em argumentos tão diferentes entre si, que é quase impossível identificar o denominador comum entre as diferentes interpretações. Ao mesmo tempo, veremos que o uso da fórmula contribui para uma argumentação polêmica que visa à desqualificação do outro, bem como qual é a relação entre a dimensão intrinsecamente polêmica da fórmula e a argumentação polêmica que une uma fórmula particular.

\section{A dimensão polêmica intrínseca da fórmula: um exemple de debate}

Uma vez que o caráter polêmico de uma fórmula pode ser identificado em dois níveis diferentes, escolhemos mostrar, por meio de diversas trocas, diferentes "camadas" de polêmica resultante da particularidade da fórmula. Enquanto alguns estudos já se debruçaram sobre a emergência de uma polêmica em torno de uma fórmula (BRILLIANT, 2011; AMADORI, 2014), nenhum estudo, até onde sabemos, dedicou-se à relação existente entre seu caráter polêmico intrínseco e seu emprego em uma argumentação de caráter de violento confronto.

Para demonstrar como uma polêmica pode ser criada em torno da própria significação dos lexemas que compõem uma fórmula e como a indefinição inerente a esses lexemas é tão mais significativa quanto a fórmula é portadora dos problemas sociopolíticos, iremos, inicialmente, apresentar uma troca política polêmica, publicada na impressa israelense em 2011, entre Shlomo Avineri, Professor de Ciências Políticas na Universidade Hebraica de Jerusalém e jornalista renomado em Israel, e Mike Herzog, antigo General da Brigada do Exército Israelense e um dos principais negociadores entre Israel e a Autoridade Palestina, Israel e a Jordânia, Israel e a Síria, durante os diálogos de paz das últimas décadas.

Em um artigo publicado no jornal israelense Haaretz, em junho 2011, Shlomo Avineri sustenta que o fenômeno denominado "deslegitimação de Israel" não existe de fato: 
EID\&A - Revista Eletrônica de Estudos Integrados em Discurso e Argumentação, Ilhéus, n. esp. ADARR, mai.2016.

Há críticas ao controle de Israel sobre o território palestino e sua política de assentamentos. Mas é sobre isso que se argumenta, não sobre a legitimidade de Israel. Ninguém está questionando seriamente o último².

Certamente, Israel encontra-se, por vezes, em uma posição difícil, mas esta dificuldade não é de modo algum o reflexo de uma tentativa qualquer de questionar sua legitimidade:

O governo de Israel transformou deslegitimação [...] em um problema que deve ser enfrentado. Concedeu, assim, uma posição marginal e sem importância, um status fora de qualquer proporção às suas verdadeiras dimensões. [...] Tais alegações são completamente delirantes ${ }^{3}$.

Assim, falar de deslegitimação de Israel não seria apenas incorreto, mas denotaria mesmo uma exploração cínica de uma terminologia que permite não ter de fazer autocrítica:

Uma vez que é difícil defender esta política exterior, [...] em vez disso, nada poderia ser mais conveniente do que mobilizar um consenso para a batalha contra a deslegitimação. Mas este esforço é tolo, cínico e perigoso 4 .

Esta terminologia seria, aos olhos do autor, completamente mal empregada nesse propósito e, consequentemente, ela corre o risco de ser nociva a Israel:

Esse uso acrítico do termo "deslegitimação" é característico do discurso político de Israel [...], apesar das melhores das intenções, tudo isso causa danos a Israel 5 .

Em resposta aos argumentos de Avineri, Mike Herzog (s/d) publica um artigo intitulado "Não subestimem a deslegitimação de Israel", no qual tenta justificar o emprego dessa fórmula mesmo em situações em que a fronteira entre a crítica de Israel e o questionamento de sua legitimidade não é muito nítida:

2 No original: There is criticism of Israel's control of Palestinian territory and its settlement policy. But that is what the argument is about, not Israel's legitimacy. No one is seriously questioning the latter.

3 No original: Israel's government has turned delegitimization [...] into a problem that must be dealt with. It has thereby granted a marginal, unimportant position a status out of all proportion to its true dimensions. [...] Such claims are completely delusional.

4 No original: Since it is hard to defend this policy overseas, [...] nothing could be more convenient than mobilizing a consensus for the battle against delegitimization instead. But this effort is foolish, cynical and dangerous.

5 No original: Such uncritical usage of the term "delegitimization" is characteristic of Israel's political discourse [...] despite the best of intentions, all of this does damage to Israel. 
EID\&A - Revista Eletrônica de Estudos Integrados em Discurso e Argumentação, Ilhéus, n. esp. ADARR, mai.2016.

\begin{abstract}
Uma parte significativa da campanha de deslegitimação não é expressa na rejeição pura e simples de Israel, mas, ao contrário, faz isso de uma maneira mais sutil e sofisticada. Esta campanha começa geralmente com a crítica legítima, que é então ampliada para incluir o retrato de Israel como uma entidade inerentemente imoral devido ao seu nascimento, essência e caráter. O desafio para aqueles que lidam com este problema é tentar limpar a "zona cinzenta" em que a crítica legítima e a deslegitimação estão imbricadas. Este não é um desafio simples [...]. Esta tendência não deve ser subestimada [...]. Isto não é apenas um problema de diplomacia pública ${ }^{6}$.
\end{abstract}

Em outras palavras, Herzog expressa não somente seu desacordo com as posições de Avineri, mas também deixa entender que é seu adversário que não se dá conta do perigo existente. Certamente, essa troca polêmica pertence ao tipo daquelas que concernem à própria significação de uma fórmula e, no contexto desse confronto específico, podemos observar que o debate se aproxima do que Fogelin chama "profundo desacordo". Neste caso:

[...] engajar-se em uma troca argumentativa pressupõe um quadro de compromissos partilhados; a linguagem do argumento pode persistir, mas tornase inútil, uma vez que faz um apelo a algo que não existe: um quadro compartilhado de crenças e preferências (FOGELIN, 2005, p. 6)7.

$\mathrm{Na}$ terminologia de Marc Angenot, trata-se da ideia de "rupturas cognitivas":

Meu adversário não parece pertencer ao meu "universo mental". Ele ou ela parece não entrar em conflito comigo unicamente pela escolha de seu argumento ou por sua hierarquia de valores, mas pelo seu próprio modo de decifrar o mundo (ANGENOT, 2002, p. 515).

Os dois oponentes enxergam bem os mesmos eventos, mas os interpretam de maneira completamente diferente, pois suas premissas são compatíveis. Assim, Avineri e Herzog não estão, de fato, em vias de debater a existência do fenômeno da “deslegitimação de Israel”, uma vez que, na base,

6 No original: A significant portion of the delegitimization campaign is not expressed in the outright rejection of Israël but rather, does so in a more nuanced and sophisticated manner. This campaign usually begins with legitimate criticism, which is then expanded to include the portrayal of Israel as an inherently immoral entity due to its birth, essence, and character [... The challenge to those dealing with this issue is to try and clear out the "gray area" in which legitimate criticism and delegitimization reside in tandem. This is not a simple challenge [...] This trend must not be underestimated $[\ldots]$ This is not just a problem of public diplomacy.

7 No original: [...] engaging in an argumentative exchange, presupposes a background of shared commitments; the language of argument may persist, but it becomes pointless since it makes an appeal to something that does not exist: a shared background of beliefs and preferences (FOGELIN, 2005, p. 6).

8 No original: My adversary does not appear to belong to my "mental universe". He or she seems not to clash with me by his or her choice of arguments alone, or his or her hierarchy of values, but by his or her very way of deciphering the world (ANGENOT, 2002, p. 515). 
EID\&A - Revista Eletrônica de Estudos Integrados em Discurso e Argumentação, Ilhéus, n. esp. ADARR, mai.2016.

eles não estão de acordo sobre o que isso significa. Para Avineri, tratar-se-ia de uma declaração aberta que expõe a ilegitimidade (do ponto de vista legal) da entidade do Estado de "Israel" por parte dos países que mantêm relações diplomáticas com Israel: "Nenhum país que mantém relações diplomáticas com Israel nunca fez qualquer reclamação contra a sua existência legítima" Para Herzog, mesmo o deslizamento de uma crítica legítima da política de Israel em direção à insinuação de sua ilegitimidade moral representa a encarnação da "deslegitimação de Israel”: "Na sua essência, é a rejeição da legitimidade de Israel como o Estado-nação do povo judeu"10. Trata-se de uma referência a dois tipos diferentes de legitimidade, mas também a dois tipos diferentes de Israel: para um, é o Estado fundado em 1948 e internacionalmente reconhecido; para o outro, é o próprio conceito de autodeterminação aplicado ao povo judeu.

Se o acordo nessa polêmica parece ser impossível de alcançar, o mesmo necessariamente não acontece quando a polêmica, em vez de se concentrar na própria significação, explora a fórmula em sua argumentação. No caso dos dois próximos exemplos, a polêmica não se refere ao que "deslegitimação de Israel" significa, pois a fórmula é, antes de tudo, explorada para alcançar, com força, o objetivo principal: a desqualificação do adversário.

\section{A utilização polêmica da fórmula no debate político}

\subsection{Os debates parlamentares polêmicos no Knesset, o parlamento de Israel}

Para análise, selecionamos dois debates parlamentares do mesmo tipo, onde os actantes da polêmica são também os mesmos: são dois "debates das 40 assinaturas", um tipo de debate solicitado pelos parlamentares israelenses (com um mínimo de quarenta assinaturas) do qual o Primeiro Ministro tem a obrigação de participar. Antes do início do debate em si, o Primeiro Ministro tem a oportunidade de se dirigir ao Knesset (o parlamento israelense) e, em seguida, o Líder da Oposição é solicitado a fazer um discurso. Enquanto o debate pode ser solicitado pelos parlamentares para discutir qualquer assunto da atualidade que julguem importante para a ciência do Primeiro Ministro, ocorre que, muitas vezes, os discursos do Primeiro Ministro e do Líder da

9 No original: No country that maintains diplomatic relations with Israël has ever made any claim against its legitimate existence.

10 No original: At its heart, it is the rejection of Israel's legitimacy as the nation-state of the Jewish people. 
EID\&A - Revista Eletrônica de Estudos Integrados em Discurso e Argumentação, Ilhéus, n. esp. ADARR, mai.2016.

Oposição voltam-se, principalmente, para a "glorificação" da própria pessoa e tentativa de destruir o outro, entrando assim no esquema de um confronto polêmico clássico.

As duas primeiras trocas aconteceram em março de $2010^{11}$ e as outras duas em janeiro de $2011^{12}$. Nos dois casos, o primeiro a tomar a palavra é o Primeiro Ministro Benjamin Netanyahou, e é a Líder da Oposição Tsipi Livni que se dirige em seguida ao parlamento - e, com frequência, diretamente ao Primeiro Ministro, sendo dois casos particularmente evidentes de "duplo direcionamento" (cf. Siess \& Valency, 2002) - com dois discursos de caráter fortemente polêmico.

A polêmica dessas trocas estar mais evidente do que a tentativa de desqualificação do adversário não é absolutamente velada. De um lado, o Primeiro Ministro declara várias vezes que ele espera ataques de ordem pessoal por parte de seu oponente: “Mas mesmo assim eu tenho um problema com os insultos, as calúnias pessoais [...] que se tenha uma discussão concreta, tempestuosa, mas respeitando as regras de polidez recíproca, sem evoluir para uma violência verbal”. Do outro lado, Tsipi Livni concentra a esmagadora maioria de seus argumentos ao descrédito total da pessoa e das ações de Netanyahou. Este último, por sua vez, recorreu a uma série de argumentos ad hominem contra Tsipi Livni em seu discurso de 2011. Sob o pretexto de citar argumentos de outro parlamentar, ele também entra em um mecanismo polêmico do qual não participava inicialmente:

E você diz, ela não é digna de governar, ela não é capaz de ser Primeiro Ministro. Você disse em 5 de janeiro deste ano, você falou da Líder de seu partido que ela prejudica o Estado de Israel. Você disse em 21 de janeiro que Livni reage de forma histérica e temerosa. Você lhe deu um pouco de crédito, você disse que Livni é simpática, mas ela não está pronta para fazer escolhas difíceis.

\subsection{A construção do ethos de Netanyahou}

A maior parte dos dois discursos de Netanyahou concentra-se no esforço de criar um consenso em torno de sua própria pessoa, e não na desqualificação do outro.

Deixando de lado os ataques indiretos contra Tsipi Livni mencionados acima, o Primeiro Ministro aproveita o tempo destinado à sua fala para

11 Disponível em: http://www.pmo.gov.il/MediaCenter/Speeches/Pages/speech40sign030310.aspx 12 Disponível em: http://www.pmo.gov.il/MediaCenter/Speeches/Pages/speech40signo40111.aspx 
EID\&A - Revista Eletrônica de Estudos Integrados em Discurso e Argumentação, Ilhéus, n. esp. ADARR, mai.2016.

informar o parlamento sobre seu trabalho e o de sua equipe durante os últimos meses:

Este debate me dá a possibilidade, enquanto Primeiro Ministro, de ouvir os parlamentares, mas também de responder [...] sobre o que aconteceu ou o que governo fez ou o que aconteceu no país.

E, também, para evidenciar o consenso crescente na esfera internacional em torno de suas ações:

A comunidade internacional e, sem dúvida, seus estados líderes, compreendem bem mais o caráter do programa [nuclear iraniano], os perigos desse programa, e eu diria que isso é compartilhado por todos os estados do mundo e quase todos os estados do Oriente Médio, incluindo os estados árabes [...] no domínio diplomático, entre nós e os Palestinos [...] o mundo compreende no final das contas e como! Compreende que esse governo está disposto a negociar, que fizemos escolhas difíceis para fazer avançar essas negociações, que dissemos e fazemos coisas.

Do mesmo modo, haveria em Israel um verdadeiro consenso na população com relação a suas ações, em particular no que tange à questão da liberação de Jonathan Pollard, um cidadão dos Estados-Unidos de religião judaica que, em 1987, foi condenado prisão perpétua em seu país por espionagem a proveito de Israel ${ }^{13}$ :

Inicialmente, eu gostaria de lhes dizer algo que congrega a nós todos, tanto parlamentares quanto o povo todo: eu me refiro à libertação de Jonathan Pollard [...]. Eis aqui o que eu escrevi. Eu sei que isso reflete os sentimentos de todos nós.

Se, em seu discurso de 2010, Netanyahou basicamente sintetiza as ações conduzidas por seu governo nas semanas que antecederam ao debate, em seu discurso de 2011, ele reduz essa síntese a um trecho mais pertinente que se concentra quase exclusivamente na questão de Pollard e nas escolhas tomadas pelo Primeiro Ministro, para brevemente tocar no sucesso econômico e educativo de seu governo no ano anterior, antes de dedicar o encerramento de seu discurso aos ataques diretos (e indiretos) contra a Líder da Oposição.

Podemos então salientar um esforço argumentativo dirigido, sobretudo, ao reforço de seu ethos de Primeiro Ministro, que se desenvolve em três eixos principais: o primeiro é o do líder que escuta as demandas do povo e das

13 Em maio de 1995, Pollard obteve a nacionalidade israelense e, em 1998, ele foi oficialmente reconhecido por Israel como espião do Mossad - o serviço secreto do Estado de Israel. 
EID\&A - Revista Eletrônica de Estudos Integrados em Discurso e Argumentação, Ilhéus, n. esp. ADARR, mai.2016.

pessoas em dificuldade, como Jonathan Pollard; o segundo eixo é o do líder do Povo Judeu que se preocupa com a herança judia transmitida à jovem geração israelense e que dedica seus esforços à reafirmação da judaicidade da Terra de Israel e do patrimônio cultural do Estado - esta parte de seu ethos é particularmente importante para Netanyahou, pois ela representa um dos pontos cardiais de seu sucesso junto a seu eleitorado e encontramos, de fato, esse mesmo ponto quase um ano depois, em seu discurso de 2011; o terceiro, finalmente, é o do líder capaz de fazer escolhas difíceis e de exigir o mesmo dos seus:

Eu lhe disse, na mesma ocasião, que eu me comprometo diante de você, Jonathan, que o Estado de Israel e eu pessoalmente faremos tudo o que for possível para conduzi-lo à sua família, conduzi-lo ao seu povo, conduzi-lo a Israel [...]. Eu encontrei o Presidente Bush durante sua visita a Jerusalém, eu Ihe pedi para libertar Jonathan Pollard. Eu Ihe escrevi uma carta oficial próximo ao final de seu mandato, de Bush. Quando fui eleito Primeiro Ministro pela segunda vez, eu levantei a questão durante minha primeira visita a Washington, por ocasião de uma conversa com o Presidente Obama, e, a partir de então, eu tive a oportunidade de levantar essa questão várias vezes com outros Chefes de Estado, incluindo os últimos meses.

É este último aspecto do ethos apresentado por Netanyahou que desempenha um papel particularmente importante na desqualificação de seu adversário, uma vez que é precisamente sobre a fragilidade de Tspi Livini e sua incapacidade de fazer escolhas que se fundamenta o ataque pessoal contra ela.

Nessas duas trocas em questão, são as duas dirigidas a Tpisi Livni que representam até o fim o jogo da polêmica e que, no interior de sua argumentação, fazem uso da fórmula "deslegitimação de Israel".

\subsection{Os ataques da Líder da Oposição contra o Primeiro Ministro}

O discurso de 2010 de Tsipi Livni avança sobre duas vias paralelas e complementares: de um lado, a desqualificação da pessoa de Netanyahou e de suas ações; de outro, a ênfase nas ações positivas do governo anterior, em que o partido Kadima (à frente do qual se encontra Livni em 2010) estava no poder enquanto Netanyahou era o Líder da Oposição. A justaposição dos malefícios de Netanyahou e dos benefícios de Livni diz respeito, principalmente, às intenções das duas pessoas: enquanto Netanyahou age apenas por interesse pessoal, movido por um desejo insaciável de "ocupar o lugar do Primeiro Ministro", Livni e seu governo agem segundo os interesses 
EID\&A - Revista Eletrônica de Estudos Integrados em Discurso e Argumentação, Ilhéus, n. esp. ADARR, mai.2016.

do povo e do Estado de Israel, apoiando-se ao máximo no total suporte da comunidade internacional:

Senhor Primeiro Ministro, o fato de ocupar o cargo de Primeiro Ministro não significa que o senhor seja um líder. Um ano passou - e nada. Nada. O senhor trabalhou duro para chegar lá [onde está]. O senhor esteve na oposição, o senhor fechou acordos, fez coligações, ocupou o seu lugar. [...] Um ano se passou e a folha está vazia. Nada. Poderíamos escrever que o senhor ocupou o posto. Eu, eu sei o que nós deixamos para esse governo. Segurança, depois da Operação Plomb Durci e depois também da guerra do Líbano; nós devolvemos a Israel sua força de dissuasão e conquistamos a calma. Nós deixamos as negociações internacionais em pleno funcionamento, que davam passos difíceis e que respiravam. [...] Eu, eu sei o que nós deixamos. Muitas vezes, nós nos guiamos seguindo uma estratégia que tinha um objetivo [...], enquanto $o$ mundo inteiro sustentava essas negociações. Negociações duras, complicadas, mas negociações que se baseavam em uma relação de confiança não apenas entre as duas partes, mas também entre nós e o mundo. Nós, Senhor Primeiro Ministro, acreditava-se em nós [... ]. Desde que o senhor se apropriou das coisas, Israel tornou-se um estado pária [...]. Eu não fui contar ao público para mostrar o quanto eu levo em consideração nossos interesses [...]. A diferença entre nós é que eu acredito que, para chegar a uma solução, são necessárias verdadeiras negociações [...]. Eu não renunciei a nenhuma das coisas que o senhor relatou à direita e à esquerda.

O desejo de Netanyahou de "sobreviver" em vez de dirigir um Estado de maneira responsável retorna igualmente várias vezes ao discurso de Lavni de 2011:

Seu objetivo é sempre chegar ao poder e de aí ficar [...]. E tudo isso para poder ser eleito ou parar nomear um governo [...]. E agora o objetivo é dizer o que é necessário dizer. Há, aqui, uma dose precisa para poder dizer o que é necessário, para [...] não ter de fazer o que é necessário, com o intuito de novamente ser eleito pela direita no próximo governo.

Paralelamente, um segundo fio condutor de desqualificação do adversário corre ao longo dos discursos de Livni de 2010 como nos de 2011. Trata-se da fragilidade de Netanyahou, o qual não saberia tomar as decisões corajosas e importantes para o Estado de Israel:

Havia um Ministro das Finanças que não cedia a todo mundo, a todos aqueles a quem o senhor paga hoje pelos interesses sobre tudo o que há. [...]. O senhor tem medo de que seus parceiros naturais do próximo orçamento o chantageiem? O senhor sabe o que vai acontecer e sabe também que está frágil o bastante para pagar. [... ]. O senhor permite a qualquer pessoa denegrir tudo 0 que funciona, tudo o que simboliza a democracia de Israel, tudo o que a protege. [...]. O senhor é o Primeiro Ministre - seja Primeiro Ministro uma vez só, faça o que é justo, condene quem for preciso. Proteja quem for preciso. Eu não o perdoarei se por causa de sua fragilidade pessoal ou política o senhor vender ao povo o que não for possível (2010). 
EID\&A - Revista Eletrônica de Estudos Integrados em Discurso e Argumentação, Ilhéus, n. esp. ADARR, mai.2016.

Arik Sharon era um Primeiro Ministro, quando ocupava aqui o posto de Primeiro Ministro [...]. É o Primeiro Ministro que afirmou sobre o senhor: "ele é influenciável" [...]. Hoje o senhor é prisioneiro do próprio governo que o senhor criou [...]. Há pessoas boas que acreditam que o senhor foi eleito para fazer escolhas (2011).

\subsection{A fórmula "deslegitimação de Israel" como arma polêmica}

E é se inserindo no âmago desta argumentação polêmica feita de tentativas de destruição da pessoa do Primeiro Ministro que os dois argumentos que incluem a fórmula "deslegitimação de Israel” aparecem:

É verdade que o processo de deslegitimação do Estado de Israel começou mais cedo. Isso não começou durante seu mandato. Mas sua política tornou-se um instrumento nas mãos daqueles que dão continuidade ao processo. E, seguramente, seus argumentos não são justificáveis. Eu sou a primeira a dizer que, há muitos anos, existe um processo de deslegitimação do Estado de Israel. E o próprio fato de que se fale de Israel, empregando atualmente termos tais como apartheid, é um fato que devemos enfrentar juntos. E o fato de que um parlamentar participe desse tipo de missão ${ }^{14}$ é algo que deve ser condenado por todos nós. E eu estou pronta, meu Senhor Primeiro Ministro, para ser a voz do Estado de Israel, para lutar por nosso direito de combater o terrorismo onde quer que ele esteja, para lutar por nosso direito à autodefesa. [Eu estou pronta para] agir no mundo para que impeçamos o Iran de se organizar. Eu posso representar o Estado de Israel. Eu não posso representar sua política (2010).

O senhor tem essa tendência a rejeitar as falhas daqueles que estão do outro lado do oceano, mas, no final das contas, Obama é da mesma linhagem do Presidente Bush em sua visão dos dois estados-nações. Nada mudou do ponto de vista da perspectiva.

$E$, então, a solução - quando de fato não acontece nada, e nós estamos em um impasse, e a situação de Israel piora cada vez mais, e há uma campanha crescente de deslegitimação contra a existência do Estado enquanto Estado judeu - e então é aí que normalmente o senhor lança a palavra "unidade". É importante que nós estejamos todos unidos contra. Jamais para algo, somente contra. Nós nos definimos, em sua perspectiva das coisas, em função das ameaças vizinhas.

Eu não posso deixar de me questionar: unidos em torno de que nesta campanha de deslegitimação? Em torno dos discursos do Ministério das Relações Exteriores que joga lenha na fogueira da deslegitimação e o seu silêncio embaraçoso. Em torno dos discursos de paz do Ministério da Defesa a quem o senhor acena com um olá, admitindo que ele expresse sua posição pessoal, não a do governo. Unidade em torno de um terrível vazio que o senhor criou em torno de si mesmo (2011).

14 Trata-se da parlamentar israelense oriunda do setor arabe Hanin Zoabi, que se juntou à pequena frota turca dita de ajuda humanitária determinada a romper o embargo a Gaza imposto por Israel em maio de 2010. 
EID\&A - Revista Eletrônica de Estudos Integrados em Discurso e Argumentação, Ilhéus, n. esp. ADARR, mai.2016.

Uma vez que, conforme visto, a indefinição inerente a essa fórmula se traduz na falta de uma definição do que é a "deslegitimação de Israel", é por meio de uma análise das definições discursivas (GIAUFRET COLOMBANI \& PARDI, 2010; RIEGEL, 1987) presentes no texto que nós podemos deduzir o que o locutor compreende desta fórmula em cada emprego (AMOSSY, 2015).

No primeiro caso, Livni associa à "deslegitimação de Israel" tanto os discursos que definem Israel enquanto estado de apartheid quanto a intenção expressa pela parlamentar Hanin Zoabi de participar da pequena frota turca de maio de 2010. Ao mesmo tempo, ao se propor como possível porta-voz de Israel, ela declara também que está pronta para lutar pelo direito de Israel de se defender contra o terrorismo e seu puro e simples direito de autodefesa, por exemplo, contra o Iran - o debate sobre a energia nuclear iraniana é, nessa época, já muito virulento.

No caso do discurso de 2011, entretanto, a "deslegitimação de Israel" toma outro sentido: trata-se, dessa vez, de uma campanha contra a própria existência do Estado de Israel, campanha que seria agravada pelos discursos do Ministro das Relações Estrangeiras (Avigdor Liberman) e em torno da qual Netanyahou conclamaria ao povo para permanecer unido. Interessante salientar que, mesmo no discurso de 2010, a política do governo Netanyahou seria, segundo Livni, responsável pela degradação da situação de tudo no que concerne à "deslegitimação de Israel".

O sentido de nossa fórmula flutua, assim, nos discursos de Livni, entre: as ações do exterior que visam a atentar contra a legitimidade moral de Israel (tratando-o como estado de apartheid); as ações do exterior e do interior que buscam desestabilizar sua política de autodefesa (nesse sentido, a relação com a legitimidade do Estado é menos direta); as campanhas que têm por objetivo negar o direito à própria existência de Israel (a legitimidade negada, aqui, poderia ser do tipo legal como do tipo moral).

Se Livni não tem interesse em entrar novamente em uma polêmica sobre o sentido da própria fórmula, é porque, de fato, ela explora a relevância argumentativa desse sentido da fórmula: a imprecisão inerente ao sentido da "deslegitimação de Israel" lhe permite inserir a fórmula em duas sequências cujo objetivo é desqualificar ainda mais seu adversário.

No caso do discurso de 2010, o sentido das afirmações de Livni é que embora a situação de Israel diante da "deslegitimação de Israel" seja grave, ao ponto de exigir uma ação imediata por parte da própria Livni -, ela não pode 
EID\&A - Revista Eletrônica de Estudos Integrados em Discurso e Argumentação, Ilhéus, n. esp. ADARR, mai.2016.

(apesar da reconhecida urgência) resolver agir, pois a política de Netanyahou, que não fez outra coisa que piorar a situação, é indefensável ao ponto de impedir Livni de tomar posição.

No caso do discurso de 2011, em compensação, o recurso à fórmula "deslegitimação de Israel" serve para exacerbar o contraste entre a quantidade de problemas que Israel deve enfrentar e o "terrível vazio" da pessoa, das palavras e das ações de Netanyahou, que apenas sabe pedir às pessoas que se unam, sem a capacidade de lhes dizer em torno de quê.

O objetivo desqualificante dessas duas argumentações é flagrante e o trunfo que a fórmula "deslegitimação de Israel" Ihes oferece também é evidente. "Surfando" sobre o caráter indefinido da fórmula, que também está na base sua polemicidade intrínseca, Livni pode construir várias argumentações de caráter polêmico com o fim de anular esse mesmo ethos tão zelosamente construído por Netanyahou em seus discursos anteriores. De um lado, então, a Líder da Oposição pode polemizar sobre ações de Netanyahou e argumentar que - com toda boa vontade do mundo e apesar da gravidade da "deslegitimação de Israel" em curso - para ela é impossível defender o indefensável (quer dizer a política do Primeiro Ministro). Por outro lado, a fórmula lhe permite atingir uma espécie de clímax nos ataques pessoais dirigidos a Netanyahou (a parte que implica a deslegitimação se encontra, de fato, no final de seu discurso) e demolir, definitivamente, a imagem de líder que se preocupa com cada um dos membros de seu povo e que não cansa de insistir junto ao Presidente dos Estados Unidos que liberte um deles: imagem construída anteriormente em seu discurso.

Ao mesmo tempo, seguramente, esses mesmos argumentos contribuem para a busca de um consenso em torno de sua pessoa enquanto Líder de Oposição, mas também enquanto única alternativa plausível ao Primeiro Ministro. Disposta a se sacrificar pelo bem comum, capaz de fazer escolhas difíceis sem disso se vangloriar (ao contrário de Netanyahou), Livni é a única que pode lutar de maneira eficaz contra a "deslegitimação de Israel" e reconduzir o País sobre uma via que goza da aprovação do mundo (que, em seus próprios termos, confiava em Livni, mas não acreditava em Netanyahou). 
EID\&A - Revista Eletrônica de Estudos Integrados em Discurso e Argumentação, Ilhéus, n. esp. ADARR, mai.2016.

\section{Conclusão}

Vimos como as trocas polêmicas analisadas podem se concentrar sobre a significação de uma fórmula, cujos lexemas que a constituem se caracterizam por uma indefinição quase impossível de dissipar, e também sobre assuntos que não giram forçosamente em torno da "deslegitimação de Israel". No segundo caso, o emprego da fórmula no interior de uma argumentação polêmica é explicável por sua adaptabilidade extrema, que permite ao locutor construir argumentos muito diferentes entre eles, recorrendo a uma mesma fórmula cujo efeito patêmico é muito forte e o valor argumentativo é evidente.

No que diz respeito ao projeto de persuasão típico dos esforços argumentativos, no caso das trocas polêmicas analisadas, podemos ver claramente que o objetivo principal dessa desqualificação total do outro é consolidar seus próprios adeptos às suas posições mais do que de persuadir os que pensam de maneira diferente. Não há, nessas trocas, nenhuma vontade de convencer a parte contrária nem aqueles que poderiam seguir a sessão do parlamento. A polêmica é explorada aqui em seu aspecto mais radical - o descrédito lançado sobre o outro - para bem mais reforçar o ethos do locutor e o consenso em torno de sua pessoa. Também não podemos, de fato, falar de consolidação do consenso em torno de posições da locutora na medida em que, no final das contas, nenhuma posição autêntica é desenvolvida nos discursos da Líder da Oposição, com exceção da simples oposição ao outro. Paradoxalmente, a censura que Livni faz a Netanyahou no final de seu discurso de 2011 (parafraseando: "segundo ele, é necessário sempre estar unidos contra qualquer coisa, jamais para") é, de todo modo, retomada em sua própria argumentação, que se caracteriza não pela elucidação de suas posições e das razões pelas quais seus adeptos deveriam segui-la, mas, antes, pela afirmação desse contra que conclama a se unir a ela, contra a pessoa do primeiro Ministro.

A relação entre o caráter intrinsecamente polêmico da fórmula e seu emprego em uma argumentação polêmica gira então em torno de uma indefinição que caracteriza a fórmula. Essa indefinição, que está na base do aspecto polêmico inerente à “deslegitimação de Israel”, também está na base da possibilidade que os locutores têm de empregar essa mesma fórmula na exacerbação uma troca polêmica. 
EID\&A - Revista Eletrônica de Estudos Integrados em Discurso e Argumentação, Ilhéus, n. esp. ADARR, mai.2016.

\section{Referências}

AMADORI, S. "Democrazia digitale": usages politiques et rhétoriques d'une formule dans le cadre des élections politiques italiennes de 2013. Repères DoRiF, n. 5, 2014.

AMOSSY, R. The Functions of Polemical Discourse in the Public Sphere. In: SMITH, M.; WARNICK, B. (eds.). The Responsibilities of Rhetoric. Long Grove, Illinois: Waveland Press, Inc., 2010. p. 52-61.

. La coexistence dans le dissensus. Semen, n. 31, p. 25-42, 2011.

. Apologie de la polémique. Paris: PUF, 2014.

- La polémicité des définitions en discours. La formule «délégitimation d'Israël » dans la presse française. In : ANGERMULLER, Johannes; GILLES, Philippe (eds). Analyse du discours et dispositifs d'énonciation. Autour des travaux de Dominique Maingueneau. Limoges: Lambert-Lucas, 2015.

; BURGER, M. Introduction: la polémique médiatisée. Semen, 31, 2011.

ANGENOT, M. La Parole pamphlétaire. Typologie des discours modernes. Paris: Payot, 1982.

. Doxa and Cognitive Breaks. Poetics Today, v. 23, n.3, p. 513-537, 2002.

. Dialogue de sourds. Traité de rhétorique antilogique. Paris: Mille et une nuits, 2008.

BOUDON, R. Le juste et le vrai. Paris: Fayard, 1995.

BRILLIANT, M. L'émergence de la polémique autour de la formule «immigration choisie » dans la presse française (janvier-juillet 2005). Semen, n. 31, 2011.

BURGER, M. Une caractérisation praxéologique du désaccord polémique: ce qu'informer dans les médias veut dire. Semen, n. 31, 2011.

BRES, J. Savoir De Quoi on Parle: Dialogue, Dialogal, Dialogique; Dialogisme, Polyphonie... In: BRES, Jacques; HAILLET, Pierre Patrick; MELLET, Sylvie; NOLKE, Henning; ROSIER, Laurence (éds). Dialogisme et Polyphonie. Approches linguistiques. Collection Champs linguistiques. Bruxelles: De Boeck Supérieur, 2005. p. 47-61.

CISLARU, G. Etude sémantique et discursive du nom de pays dans la presse française. Paris, 2005. Thèse de Doctorat - Université de Paris 3, Sorbonne Nouvelle.

DASCAL, M. Dichotomy in Debate. In: IONESCU-RUXANDOIU, L.; HOINARESCU, L. (eds.). Cooperation and Conflict in Ingroup and Intergroup Communication. Bucharest: Editura Universitatii dom Bucuresti, 2006. p. 21-34.

; KNOLL, A. Cognitive systemic dichotomization in public argumentation and controversies. 9th International Conference of the Ontario Society for the Study of Argumentation (OSSA). Proceedings (Ed. F Zenker). Windsor, ON, University of Windsor, 2011.

ELLIS, N. La "délégitimation d'Israël”: usage du flou et positionnements stratégiques chez Obama, Abu Mazen et Netanyahou. Repères DoRiF, n. 5, 2014. 
EID\&A - Revista Eletrônica de Estudos Integrados em Discurso e Argumentação, Ilhéus, n. esp. ADARR, mai.2016.

FOGELIN, R.J. The Logic of Deep Disagreements. Informal Logic, 25, no. 1, p. 3-11, 2005.

HAARETZ. No one is questioning Israel's legitimacy. Disponível em: http://www.haaretz.com/print-edition/opinion/no-one-is-questioning-israel-slegitimacy-1.370169.

GRASS, T. La traduction comme appropriation: le cas des toponymes étrangers. Meta: journal des traducteurs / Meta: Translators' Journal, 51, p. 660-670, 2006.

HERZOG, M. Don't Underestimate the delegitimazation of Israel. Globes - Israel's Business Arena. Disponível em: http://jppi.org.il/uploads/michael_herzogDont_Underestimate_the_Delegitimization_of_Israel.pdf.

KERBRAT-ORECCHIONI, C. La polémique et ses définitions. In : . La parole polémique. Lyon: Presses Universitaires de Lyon, 1980. p. 3-40.

KRIEG-PLANQUE, A. La notion de "formule" en analyse du discours. Paris: Presses Universitaires de Franche-Comté, 2009.

. Analyser les discours institutionnels. Paris: Armand Colin, 2012.

MAINGUENEAU, D. Sémantique de la polémique: discours religieux et ruptures idéologiques au XVIle siècle. Lausanne: L'Age d'homme, 1983.

MARCELLESI, J-B. Éléments pour une analyse contrastive du discours politique. Langages, n. 23, p. 25-56, 1971.

MICHELI, R. Quand l'affrontement porte sur les mots en tant que mots: polémique et réflexivité langagière. Semen, n. 31, 2011.

PAVEAU, M-A. Le toponyme, désignateur souple et organisateur mémoriel. L'exemple du nom de bataille. Mots - Les langages du politique, n. 86, 2008.

PLANTIN, C. Des polémistes aux polémiqueurs. In. DECLERQ, Gilles; MURAT, Michel; DANGEL, Jacqueline (éds). La parole polémique. Paris: Champion, p. 377-408, 2003.

SIESS, J.; VALENCY, G. (éd.). La double adresse. Paris: L'Harmattan, 2002.

Como citar:

ELLIS, Nadia. A fórmula "deslegitimação de Israel” entre polêmica intrínseca e argumentação polêmica. Trad. Jocilene Santana Prado e Eduardo Lopes Piris. EID\&A Revista Eletrônica de Estudos Integrados em Discurso e Argumentação, Ilhéus, n. esp. ADARR, p. 162-182, mai.2016. 